\title{
Chlorantraniliprole application differentially affects adult emergence of Sympetrum dragonflies in rice paddy fields
}

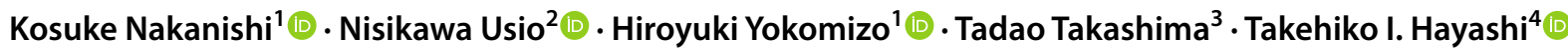

Received: 2 November 2020 / Revised: 2 November 2021 / Accepted: 8 November 2021 / Published online: 22 November 2021

(c) The Author(s) 2022, corrected publication 2022

\begin{abstract}
Rice paddy fields are important habitat for many dragonfly species. In Japan, populations of dragonflies inhabiting rice paddies, in particular Sympetrum (Odonata: Libellulidae), have decreased greatly in the last few decades. A major cause of the decline has been suggested to be the use of systemic insecticides (e.g., phenylpyrazole and neonicotinoid) in nursery boxes of rice seedlings. In this study, we examined the effects of chlorantraniliprole (CAP), a novel anthranilic diamide insecticide, on adult emergence of Sympetrum dragonflies in ten rice paddy fields by counting their exuviae remaining on the rice plants as an abundance index. Our results suggest that CAP is a potential factor that reduced the emergence rate of S. infuscatum but not of $S$. frequens. This difference may be due to differential sensitivity to CAP, different lengths of the nymphal stage, or different effects of bottom-up controls via reduction of prey organisms that are highly sensitive to CAP.
\end{abstract}

Keywords Anthranilic diamide $\cdot$ Dragonfly $\cdot$ Exuviae $\cdot$ Odonata $\cdot$ Sympetrum frequens $\cdot$ Sympetrum infuscatum

\section{Introduction}

Insecticide use in agriculture is of concern as a major cause of insect declines worldwide (Sánchez-Bayo and Wyckhuys 2019; Forister et al. 2019; Cardoso et al. 2020; Wagner 2020). In Japan, rice paddy fields are utilized as wetland-like habitats by many species; they occupy approximately $24000 \mathrm{~km}^{2}$ (about half of the total cultivated area) (Ministry of Agriculture, Forestry and Fisheries 2019), whereas the area of natural wetlands has decreased greatly over the past century from 2110 to 820 $\mathrm{km}^{2}$ (Geospatial Information Authority of Japan, 2000). These rice fields and their irrigation systems serve as main breeding

Kosuke Nakanishi

nakanishi.kosuke@nies.go.jp

1 Health and Environmental Risk Division, National Institute for Environmental Studies, Onogawa 16-2, Tsukuba, Ibaraki 305-8506, Japan

2 Institute of Nature and Environmental Technology, Kanazawa University, Kakuma-machi, Kanazawa, Ishikawa 920-1192, Japan

3 Hakui Agricultural Cooperatives (JA Hakui), Ota-machi To 105, Hakui, Ishikawa 925-8588, Japan

4 Social Systems Division, National Institute for Environmental Studies, Onogawa 16-2, Tsukuba, Ibaraki 305-8506, Japan sites for many dragonfly (Odonata) species; as many as 31 species of a total of approximately 200 resident species use rice paddies (Uéda 1998). However, many Japanese dragonfly species have been threatened with extinction in recent decades (Kadoya et al. 2009). The application of certain types of systemic insecticides to nursery boxes of rice seedlings (i.e., the phenylpyrazole fipronil and the neonicotinoid imidacloprid) is suspected as one of the main causes of the sharp population declines of Sympetrum frequens (Odonata: Libellulidae) —one of the most common dragonfly species in Japan-in the 1990s (Nakanishi et al. 2018, 2020). By the 2010s, the population density of $S$. frequens had not recovered to pre-1990s levels, even though the use of fipronil and imidacloprid has decreased (Nakanishi et al. 2018, 2020). Other types of insecticides (e.g., cartap and chlorantraniliprole) are also suspected of limiting the population growth of $S$. frequens in addition to other agronomic factors, such as midsummer drainage and crop rotation (Nakanishi et al. 2020). Because dragonflies play an important role as common intermediate predators in both aquatic (e.g., rice paddies) and terrestrial ecosystems (Corbet 1999), it is important to detect current agronomic factors reducing their population growth for biodiversity conservation in Japanese rural areas.

A recently introduced chemical, chlorantraniliprole (CAP; Rynaxypyr $\left.{ }^{\circledR}\right)$, an anthranilic diamide insecticide, has been commonly used as a nursery box treatment for 
rice cultivation since the 2010s in Japan (Nakanishi et al. 2020). CAP has a different mode of action from neurotoxic insecticides such as pyrethroids and neonicotinoids: it acts on insect ryanodine receptors and causes excessive release of internal calcium, resulting in death by inhibiting feeding and paralyzing muscles (Lahm et al. 2007). Because CAP has high selective toxicity against insects over mammals, it has been widely used for pest control in various crops and is expected to be helpful in integrated pest management (Lahm et al. 2007, 2009). Although CAP has little adverse effect on dragonflies (adult emergence) (Kasai et al. 2016; Miyai et al. 2016; Hashimoto et al. 2020), it has higher toxicity than neonicotinoids and phenylpyrazoles to other aquatic invertebrates such as water fleas (EFSA 2013; EPA 2019). Nevertheless, little is known about its effects on aquatic organisms in production of rice paddies.

Most previous studies used small-scale lysimeters or rice paddy mesocosms to examine the effects of pesticides on aquatic communities (e.g., Hashimoto et al. 2020; Hayasaka et al. 2012; Jinguji et al. 2013; Miles et al. 2017); studies using commercial rice paddies are rare (Suhling et al. 2000). Although some observational studies of the effects of pesticides have been conducted in rice paddies, agronomic factors other than target pesticides were not properly controlled (e.g., Baba et al. 2019; Katayama et al. 2019; Wilson et al. 2007). In addition, although up to 31 dragonfly species inhabit rice paddies in Japan and several species often coexist (Uéda 1998), little is known about species differences in sensitivity to pesticides.

Here, we examined the effects of CAP application in rice paddies on the adult emergence of dragonflies of the genus Sympetrum, one of the most common genera inhabiting rice paddy fields in Japan (Uéda 1998). We conducted a field survey in commercial rice paddies with and without CAP. As an index of abundance, we recorded exuviae, which have been used before as environmental indicators in rice paddy ecosystems (Suhling et al. 2000; Baba et al. 2019; Katayama et al. 2019); we compared numbers between treatments, because exuviae are proof of success in nymphal development and adult emergence at a site, and because they provide the overall numbers of dragonflies that have emerged, being less affected by survey time compared with adult numbers (Raebel et al. 2010). We analyzed the effects of CAP on the emergence of each Sympetrum species, taking account of other environmental factors such as water depth, and thereby examined interspecific differences in sensitivity to CAP. We hypothesized that CAP application would decrease the emergence of Sympetrum species in rice paddies, as it does in many other aquatic invertebrates (EFSA 2013; EPA 2019).

\section{Methods}

\section{Species investigated}

Sympetrum is a common genus in rice paddy fields throughout Japan (Uéda 1998). In the study area, S. frequens and $S$. infuscatum are numerically dominant. Both species have a univoltine life cycle. They lay eggs in drained paddies in autumn. The main reproductive season of S. infuscatum is August to September (Watanabe et al. 2004), whereas that of $S$. frequens is September to November (Uéda 1988). The eggs overwinter and hatch the following spring (around April), soon after the start of irrigation. The nymphs grow while feeding on other aquatic organisms, such as sludge worms, microcrustaceans, and midge and mosquito larvae, and they emerge as adults in June and July (Inoue and Tani 2010). The nymphal period of $S$. infuscatum is about 2 weeks longer than that of $S$. frequens, and $S$. infuscatum nymphs grow larger than $S$. frequens nymphs (Jinguji and Tsuyuzaki 2009).

\section{Experimental design}

To examine the effect of CAP application on adult emergence, we used ten adjacent commercial rice paddy fields in Hakui City, Ishikawa Prefecture, Japan (36.920317 N, 136.784380 E; Fig. 1). The study site was located in a paddydominated landscape of Ouchi Plain. The ten paddy fields were situated in two blocks (A and B) separated by a road, with opposite water flow directions. Individual fields were approximately 0.3 ha. We assigned treatments in consultation with the farmer so as to create identical conditions apart from the insecticide application; six fields were treated with CAP and the other four fields were used as controls. The fields grew rice (Oryza sativa L. 'Koshihikari') under the conventional management regime in the region except for the application of CAP to rice seedlings. In this region, CAP has been used during nursery or rice planting since 2015 , including in our study fields. All study fields had been cultivated under the same regime with equal amounts of pesticides (including CAP) and fertilizers in the previous year. The CAP-treated fields were treated with a commercial agrochemical product, Dr. Oryze ${ }^{\circledR}$-Ferterra ${ }^{\circledR}(0.75 \%$ granular CAP and $24 \%$ granular probenazole, Hokko Chemical Industry Co., Ltd., Tokyo, Japan), at $10 \mathrm{~kg} \mathrm{ha}^{-1}$ (recommended dose) just to the side of the rice seedlings at the time of transplantation (18-20 May 2019). The fields were flooded continuously from 7-8 May to 22-25 June, and then temporarily drained (midsummer drainage). After the midsummer drainage began, they were irrigated intermittently every 4 days or so until 30 August. 
Fig. 1 Plan of experimental paddy fields. Chlorantraniliprole (CAP) was applied to nursery boxes of rice seedlings later planted in the six CAP fields, but no insecticide was used in the four control fields. Cross marks indicate fields not used in the study

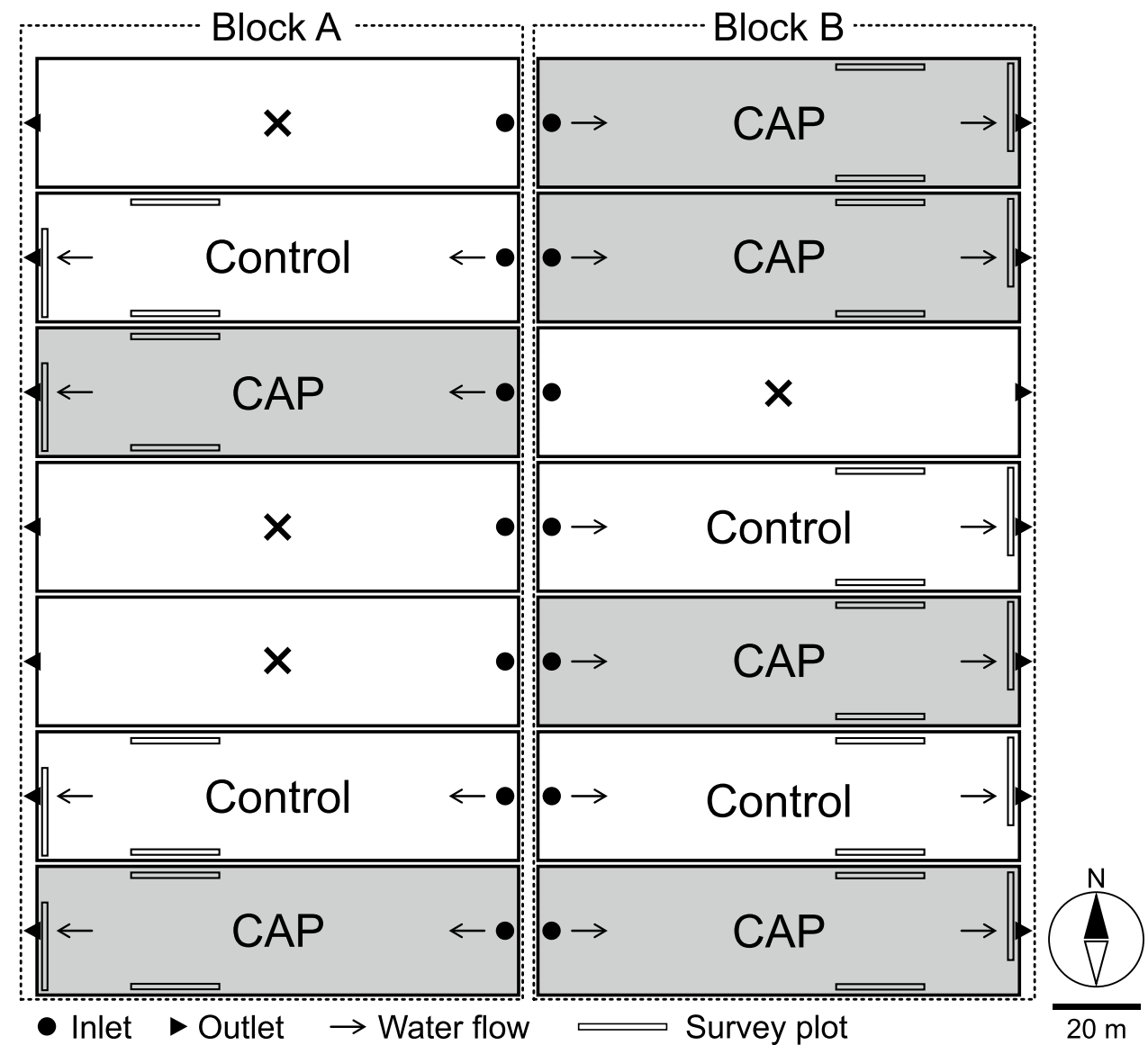

Water was supplied to each field from an inlet (via a spigot valve) and drained from an outlet (Fig. 1), so the insecticide was unlikely to contaminate other fields through the irrigation system. Since the agrochemical contained not only CAP but also probenazole, our experimental design could not isolate the effect of CAP. However, a previous study showed no statistically significant adverse effect of probenazole on S. frequens (Shimada et al. 2004), and the $\mathrm{HC}_{5}$ (hazardous concentration at which $5 \%$ of species would be affected) for aquatic ecosystems on the basis of the species sensitivity distribution of probenazole is predicted to be approximately 290 times greater than that of CAP (Nagai 2016).

\section{Dragonfly sampling and environmental measurement}

We surveyed dragonfly exuviae about every 10 days from 7 June to 30 July 2019, six times in total. Prior to the survey, we established three plots $[20 \mathrm{~m} \times 1 \mathrm{~m}$ (consisting of ca. $100 \times 3$ rows of rice plants)] alongside levees in each field (Fig. 1). At each plot, we collected exuviae from rice stems in three rows of plants according to the sampling method of Baba et al. (2019). At the respective plot, we also collected exuviae from weeds grown among rice plants. Samples were identified to species level under a stereomicroscope (LZLED-T, Kenis, Osaka, Japan) in the laboratory using the guide by Inoue and Tani (2010).

From 7 to 26 June (three measurements), prior to the start of midsummer drainage, we measured water depth in each field, because we could not control water depth among the fields. At each survey, we measured water depth (from the paddy sediment surface to the water surface) at the levee-side center of each plot using a fiberglass folding rule (Shinwa Rules Co., Ltd., Niigata, Japan). For each field, we calculated the arithmetic means of the three water depth measurements across the pre-midsummer drainage period.

\section{Statistical analyses}

To examine the effect of CAP on adult emergence, we conducted a multiple regression analysis using a generalized linear model (GLM) (Nelder and Wedderburn 1972; McCullagh and Nelder 1989). We mainly interpreted the result based on the GLM rather than a simple two-group comparison (e.g., Wilcoxon rank sum test). This is because GLM analysis can consider the effect of CAP by statistically controlling for the effects of other environmental factors. In Wilcoxon rank sum test, the severe limitation of sample size 
may not assure effective randomization (i.e., risk of random confounding: Suzuki et al. 2020) and may not provide sufficient statistical power to detect the effect of CAP under other large sources of variation (e.g., block and water depth) in the paddy fields (see Results). Therefore, we show the result of GLM analysis in the main text and provide the results of Wilcoxon rank sum test in the supplementary material.

Because the count data were over-dispersed (see Supplementary code 2.1), we applied a negative binomial distribution (log-link function) to the GLM (McCullagh and Nelder 1989; Crawley 2013). We developed the following model, which takes into account the effects of blocks and water depth:

$\log \left(\lambda_{i}\right)=\alpha+\sum_{j=1}^{J} \beta_{j} x_{j, i}+\varepsilon_{i}$

$y_{i} \sim \operatorname{Negative~} \operatorname{binomial}\left(\lambda_{i}, \theta\right)$

where $\lambda_{i}$ and $y_{i}$ represent the expected and counted total emergence numbers in the $i$ th field. $x_{j, i}$ represents $j$ th explanatory variable in the $i$ th field. $\beta_{j}$ is the coefficient for the $j$ th explanatory variable. $\alpha$ represents an intercept and $\varepsilon_{i}$ is an error term in $i$ th field. $\theta$ denote the shape parameter of the negative binomial distribution. We used block (categorical variable; block A as reference category), CAP treatment (dummy variable; 0 for control, 1 for CAP treatments), species (categorical variable; S. frequens as reference category), mean water depth (means of the three measurements), and interaction of $\mathrm{CAP} \times$ species for explanatory variables.

All analyses were conducted in R v. 3.6.1 software ( R Core Team 2019). For the GLM, we used the glm.nb function in the MASS package (Venables and Ripley 2002). All data used in the analyses and $\mathrm{R}$ code are available in online resources 1 and 2, respectively.

\section{Results}

\section{Adult emergence rates over time}

In total, we collected 475 exuviae of Sympetrum dragonflies: 239 S. frequens, 233 S. infuscatum, and 3 fragmented and thus unidentifiable to species level. Only one exuvia (Orthetrum albistylum speciosum) of the other dragonfly species was observed other than Sympetrum in the study fields. We observed adult emergence of $S$. frequens from 18 June to 18 July and of $S$. infuscatum from 26 June to 3 July (Fig. 2). Numbers fluctuated similarly between species and between treatments; numbers peaked on 26 June, although $S$. frequens began to emerge around 1 week earlier than $S$. infuscatum.

\section{Effects of chlorantraniliprole and other environmental factors}

The variations in emergence among fields in each treatment, particularly in the control, were wide (Fig. 3). GLM analysis indicated a significant block effect $(P<0.001$; Table 1$)$. Although the effect of CAP treatment was not significant $(P=0.416)$, the CAP $\times$ species interaction significantly affected emergence $(P=0.023)$. In $S$. infuscatum, emergence at the peak was $88 \%$ less in the CAP treatment relative to that in the CAP-free control. By contrast, in $S$. frequence, emergence did not differ between the two treatments. The effect of mean water depth was not significant $(P=0.815)$.

Wilcoxon rank sum test gave no statistically significant difference in the emergence numbers between treatments with and without CAP in either Sympetrum species (see Supplementary code 2.4). Factors unrelated to CAP could have caused the large variances. In this situation, the statistical power of rank-based non-parametric tests for two-group comparison was severely reduced.
Fig. 2 Temporal changes in mean numbers of emerged individuals of indicated species per field with or without chlorantraniliprole (CAP) treatment from 7 June to 30 July 2019

\section{a S. frequens}

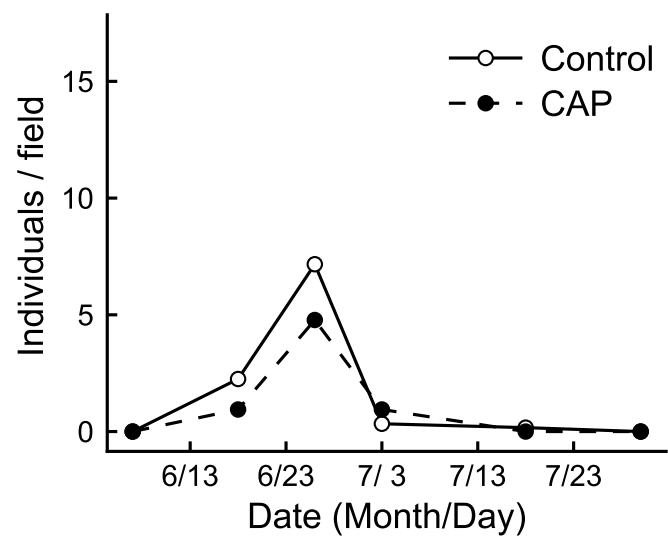

b S. infuscatum

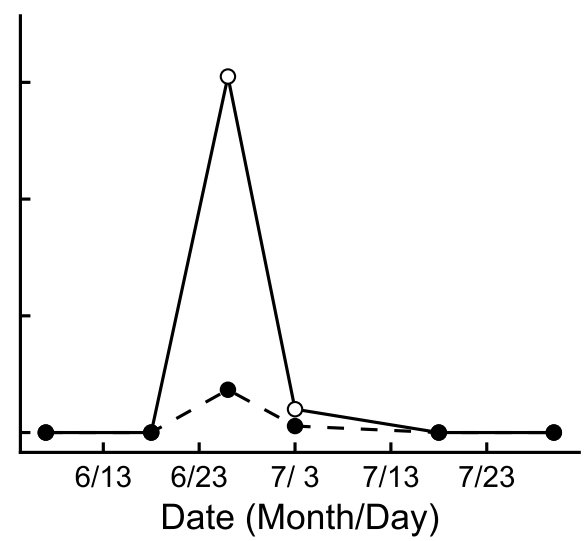


Fig. 3 Numbers of emerged individuals of indicated species in the chlorantraniliprole (CAP) and control treatments a S. frequens

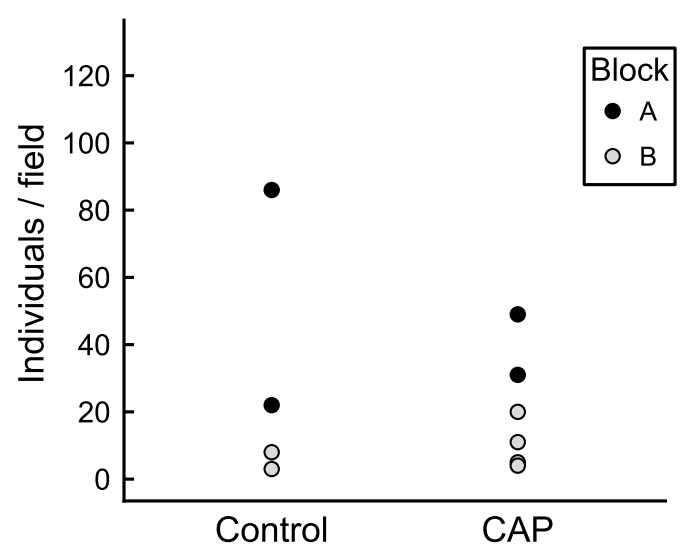

b S. infuscatum

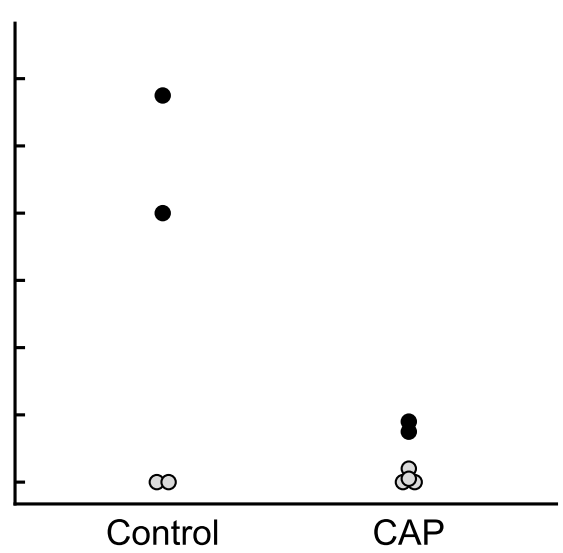

Table 1 Results of negative binomial generalized linear model examining the effect of chlorantraniliprole (CAP) and other environmental factors on the adult emergence of Sympetrum frequens and S. infuscatum

\begin{tabular}{|c|c|c|c|c|}
\hline Variable & $\begin{array}{l}\text { Estimated } \\
\text { coefficient }\end{array}$ & SE & $P$ value & \\
\hline (Intercept) & 3.837 & 1.257 & & \\
\hline Block $^{\dagger}$ & -2.503 & 0.472 & $<0.001$ & $* *$ \\
\hline CAP & 0.418 & 0.513 & 0.416 & \\
\hline Species & -0.075 & 0.546 & 0.891 & \\
\hline Water depth $(\mathrm{cm})$ & 0.039 & 0.166 & 0.815 & \\
\hline $\mathrm{CAP} \times$ species & -1.676 & 0.739 & 0.023 & $*$ \\
\hline
\end{tabular}

${ }^{\dagger}$ Block $\mathrm{A}$ as reference

\$Sympetrum frequens as reference

$* * P<0.001, * P<0.05$ (Wald test)

\section{Discussion}

We show that CAP is a potential factor that has adverse effects on the emergence of $S$. infuscatum but not of $S$. frequens (Table 1; Fig. 3). Our result contrast with preceding mesocosm and field studies. Previous studies using mesocosms or field observations showed that CAP had little adverse effect on the adult emergence of dragonflies, including Sympetrum (Miyai et al. 2016), Crocothemis, and Orthetrum (Kasai et al. 2016) in rice paddies (Kasai et al. 2016; Miyai et al. 2016). In a field study, Huynh et al. (2021) found no statistically significant difference in the adult emergence of Sympetrum dragonflies between conventional (with synthetic pesticides and fertilizers, including CAP) and natural rice paddies (without synthetic pesticides or fertilizers of any kind). Because these previous studies were not designed to elucidate the effects of CAP itself on the adult emergence of Sympetrum dragonflies, agronomic factors other than CAP were not sufficiently controlled (Miyai et al. 2016; Huynh et al. 2021).

There are three potential mechanisms for differential effects of CAP application on the two Sympetrum species and these mechanisms are not mutually exclusive. First, the two species may have different sensitivities to CAP, although there are no published data on laboratory toxicity testing on the two species. Second, a difference in life history during their nymphal periods may affect their mortality under CAP exposure. Jinguji and Tsuyuzaki (2009) reported that the mean nymphal period of $S$. infuscatum was about 2 weeks longer than that of $S$. frequens, and the body size of the last-instar nymphs of $S$. infuscatum was larger than that of $S$. frequens. Our result is consistent with this difference in their nymphal periods: the start of adult emergence of $S$. infuscatum was later than that of $S$. frequens (Fig. 1). Therefore, the nymphs of $S$. infuscatum may have been exposed longer to CAP than $S$. frequens before emergence. Third, the results of previous experimental studies of the potential prey organisms of the dragonflies suggest that the effects of CAP on adult emergence may occur indirectly through bottom-up control in the food chain. This control is expected to more strongly affect $S$. infuscatum, with its longer nymphal period. Saito et al. (2014) reported that the nymphal growth of $S$. frequens was poorer in paddies with CAP application than without. This difference may have resulted from reduced abundance of prey organisms in rice paddies with CAP application, owing to high acute toxicity to invertebrate prey such as water fleas (e.g., Cui et al. 2017; Lavtižar et al. 2015) and midges (e.g., Maloney et al. 2019; Rodrigues et al. 2015). Likewise, Hashimoto et al. (2020) showed negative effects of CAP on the abundance of some invertebrates such as sludge worms and microcrustaceans in a paddy mesocosm experiment in which CAP was applied at the same dose as here; they reported that the maximum concentration of CAP in paddy water reached $5-15 \mu \mathrm{g} / \mathrm{L}$ within a few days after transplantation of rice seedlings. If the environmental fate 
of CAP in our study was similar to the results of Hashimoto et al. (2020), CAP application may have resulted in reduced abundance of microcrustacean prey, as the $48-\mathrm{h} \mathrm{EC}_{50}$ of the water flea, Daphnia magna is 7.1-16.6 $\mu \mathrm{g} / \mathrm{L}$ (EPA 2019). This hypothesis needs to be tested in future studies.

As we used commercial rice paddies, some limitations must be resolved in evaluating the effects of CAP. First, there was a large variation in the numbers of exuviae among fields within treatments (Fig. 3), and block had statistically significant effects on numbers (Table 1). The four fields with the highest numbers of individuals of both species belonged to block A (Fig. 3). In GLM, the mean water depth had no statistically significant effects on dragonfly emergence. Furthermore, there was no significant difference in mean water depth between blocks. Nevertheless, the fields with many emergence numbers tended to have a greater mean water depth (see Supplementary code 2.5 ). Therefore, the environmental conditions such as the degree of drainage may not have been effectively randomized for the treatment and block owing to the small sample size. This variation in emergence numbers among fields within the treatment may have been caused by differences in the initial abundance of the dragonflies (i.e., numbers of eggs), which could not be readily identified before the assignment of treatments here. Future work should examine adult oviposition in each field in the year before exuviae are surveyed. Second, monitoring of environmental concentrations and the fate of CAP in the fields are needed in order to quantify the effects of the insecticide on the dragonflies. Because CAP has high persistence in paddy soil (Hashimoto et al. 2020), emergence numbers in the control treatment could have been driven down by CAP residues from previous years. Our results thus could have underestimated the effects of CAP on the dragonflies. Third, because CAP can also affect species compositions of various aquatic organisms, including prey, predators, and competitors with Sympetrum dragonflies (Kasai et al. 2016; Hashimoto et al. 2020), we need to clarify the biological interactions involving Sympetrum dragonflies (e.g., observation of predator-prey interactions) as a next step in assessing the effects in rice paddies of CAP application.

In conclusion, our results suggest that CAP is a potential factor that reduces the adult emergence of $S$. infuscatum, but not of $S$. frequens. Such interspecific difference in susceptibility to CAP may be caused by a difference in sensitivity to the insecticide or a difference in the period of the nymphal stage, as nymphs consume aquatic invertebrates that are highly sensitive to CAP. As neonicotinoid insecticides can have adverse indirect effects on insectivorous birds through the food web (Hallmann et al. 2014), CAP also may harm terrestrial ecosystems through a decrease in populations of dragonflies, which are an important food source for insectivorous birds (Corbet 1999). For biodiversity conservation in Japanese rural areas, we need to quantitatively evaluate the effects of insecticides and to seek an effective approach in the use of insecticides with minimum adverse effect on dragonflies.

Supplementary Information The online version contains supplementary material available at https://doi.org/10.1007/s10333-021-00880-5.

Acknowledgements We are grateful to Kazutoshi Maeda for permitting our survey and providing information on rice cultivation management. We thank Thien Quang Huynh (Kanazawa University) for his help with the field survey. We also thank Fumie Tanaka (National Institute for Environmental Studies) for her help with specimen identification. This study was partly supported by the Environment Research and Technology Development Fund (4-1701) of the Environmental Restoration and Conservation Agency of Japan.

Data availability All data generated or analyzed during this study are included in this published article and its supplementary information files.

\section{Declarations}

Conflict of interest The authors declare that they have no competing interests.

Open Access This article is licensed under a Creative Commons Attribution 4.0 International License, which permits use, sharing, adaptation, distribution and reproduction in any medium or format, as long as you give appropriate credit to the original author(s) and the source, provide a link to the Creative Commons licence, and indicate if changes were made. The images or other third party material in this article are included in the article's Creative Commons licence, unless indicated otherwise in a credit line to the material. If material is not included in the article's Creative Commons licence and your intended use is not permitted by statutory regulation or exceeds the permitted use, you will need to obtain permission directly from the copyright holder. To view a copy of this licence, visit http://creativecommons.org/licenses/by/4.0/.

\section{References}

Baba YG, Kusumoto Y, Tanaka K (2019) Positive effect of environmentally friendly farming on paddy field odonate assemblages at a small landscape scale. J Insect Conserv 23:467-474. https://doi. org/10.1007/s10841-019-00132-2

Cardoso P, Barton PS, Birkhofer K et al (2020) Scientists' warning to humanity on insect extinctions. Biol Conserv. https://doi.org/10. 1016/j.biocon.2020.108426

Corbet PS (1999) Dragonflies : Behavior and ecology of Odonata. Harley Books, Colcheste

Crawley JM (2013) The R book, 2nd edn. John Wiley \& Sons, Sussex

Cui F, Chai T, Qian L, Wang C (2017) Effects of three diamides (chlorantraniliprole, cyantraniliprole and flubendiamide) on life history, embryonic development and oxidative stress biomarkers of Daphnia magna. Chemosphere 169:107-116. https://doi.org/10. 1016/j.chemosphere.2016.11.073

EFSA (2013) Conclusion on the peer review of the pesticide risk assessment of the active substance chlorantraniliprole. EFSA J 11:3143. https://doi.org/10.2903/j.efsa.2013.3143

EPA (2019) ECOTOX Knowledgebase. https://cfpub.epa.gov/ecotox/ search.cfm. Accessed 11 Mar 2020

Forister ML, Pelton EM, Black SH (2019) Declines in insect abundance and diversity: We know enough to act now. Conserv Sci Pract. https://doi.org/10.1111/csp2.80 
Geospatial Information Authority of Japan (2000) Changes in Wetland Area by Prefectures. https://www.gsi.go.jp/kankyochiri/shicc himenseki2.html.

Hallmann CA, Foppen RPB, Van Turnhout CAM et al (2014) Declines in insectivorous birds are associated with high neonicotinoid concentrations. Nature 511:341-343. https://doi.org/10.1038/natur e13531

Hashimoto K, Kasai A, Hayasaka D et al (2020) Long-term monitoring reveals among-year consistency in the ecological impacts of insecticides on animal communities in paddies. Ecol Indic 113:106227. https://doi.org/10.1016/j.ecolind.2020.106227

Hayasaka D, Korenaga T, Suzuki K et al (2012) Cumulative ecological impacts of two successive annual treatments of imidacloprid and fipronil on aquatic communities of paddy mesocosms. Ecotoxicol Environ Saf 80:355-362. https://doi.org/10.1016/J.ECOENV. 2012.04.004

Huynh TQ, Oyabu A, Nomura S et al (2021) Do agrochemical-free paddy fields serve as refuge habitats for Odonata? Ecologies 2:1-15. https://doi.org/10.3390/ecologies2010001

Inoue K, Tani K (2010) All about red dragonflies. Tombow Publishing, Osaka

Jinguji H, Tsuyuzaki H (2009) Stadium construction and development of Sympetrum frequens (Selys), S. darwinianum (Selys) and $S$. infuscatum (Selys) larva. Tombo 51:38-42

Jinguji H, Thuyet DQ, Uéda T, Watanabe H (2013) Effect of imidacloprid and fipronil pesticide application on Sympetrum infuscatum (Libellulidae: Odonata) larvae and adults. Paddy Water Environ 11:277-284. https://doi.org/10.1007/s10333-012-0317-3

Kadoya T, Suda S, Washitani I (2009) Dragonfly crisis in Japan: A likely consequence of recent agricultural habitat degradation. Biol Conserv 142:1899-1905. https://doi.org/10.1016/J.BIOCON. 2009.02.033

Kasai A, Hayashi TI, Ohnishi H et al (2016) Fipronil application on rice paddy fields reduces densities of common skimmer and scarlet skimmer. Sci Rep 6:1-10. https://doi.org/10.1038/srep23055

Katayama N, Osada Y, Mashiko M et al (2019) Organic farming and associated management practices benefit multiple wildlife taxa: A large-scale field study in rice paddy landscapes. J Appl Ecol 1365-2664:13446. https://doi.org/10.1111/1365-2664.13446

Lahm GP, Stevenson TM, Selby TP et al (2007) Rynaxypyr ${ }^{\mathrm{TM}}$ : A new insecticidal anthranilic diamide that acts as a potent and selective ryanodine receptor activator. Bioorganic Med Chem Lett 17:6274-6279. https://doi.org/10.1016/j.bmcl.2007.09.012

Lahm GP, Cordova D, Barry JD (2009) New and selective ryanodine receptor activators for insect control. Bioorganic Med Chem 17:4127-4133. https://doi.org/10.1016/j.bmc.2009.01.018

Lavtižar V, Helmus R, Kools SAE et al (2015) Daphnid life cycle responses to the insecticide chlorantraniliprole and its transformation products. Environ Sci Technol 49:3922-3929. https://doi. org/10.1021/es506007q

Maloney EM, Sykes H, Morrissey C et al (2019) Comparing the acute toxicity of imidacloprid with alternative systemic insecticides in the aquatic insect Chironomus dilutus. Environ Toxicol Chem 39:587-594. https://doi.org/10.1002/etc.4639

McCullagh P, Nelder JA (1989) Generalized Linear Models, 2nd edn. Chapman \& Hall, London

Miles JC, Hua J, Sepulveda MS et al (2017) Effects of clothianidin on aquatic communities: Evaluating the impacts of lethal and sublethal exposure to neonicotinoids. PLoS ONE. https://doi.org/10. 1371/journal.pone.0174171

Ministry of Agriculture Forestry and Fisheries (2019) Statistics of Crops. http://www.maff.go.jp/j/tokei/kouhyou/sakumotu/index. html. Accessed 20 Feb 2020

Miyai K, Saito M, Jinguji H (2016) Practice and effectiveness of program of risk assessment mitigation for red dragonflies with farmers' participation. Trans Japanese Soc Irrig Drain Rural Eng $84: 201-207$

Nagai T (2016) Ecological effect assessment by species sensitivity distribution for 68 pesticides used in Japanese paddy fields. J Pestic Sci 41:6-14. https://doi.org/10.1584/jpestics.D15-056

Nakanishi K, Yokomizo H, Hayashi TI (2018) Were the sharp declines of dragonfly populations in the 1990s in Japan caused by fipronil and imidacloprid? An analysis of Hill's causality for the case of Sympetrum frequens. Environ Sci Pollut Res 25:35352-35364. https://doi.org/10.1007/s11356-018-3440-x

Nakanishi K, Uéda T, Yokomizo H, Hayashi TI (2020) Effects of systemic insecticides on the population dynamics of the dragonfly Sympetrum frequens in Japan: Statistical analyses using field census data from 2009 to 2016. Sci Total Environ 703:134499. https://doi.org/10.1016/J.SCITOTENV.2019.134499

Nelder JA, Wedderburn RW (1972) Generalized linear models. J R Stat Soc Series A 135:370-384. https://doi.org/10.2307/2344614

R Core Team (2019) R: a language and environment for statistical computing. R Foundation Statistical Computing, Vienna, Austria. https://www.r-project.org/. Accessed 10 Dec 2019

Raebel EM, Merckx T, Riordan P et al (2010) The dragonfly delusion: Why it is essential to sample exuviae to avoid biased surveys. J Insect Conserv 14:523-533. https://doi.org/10.1007/ s10841-010-9281-7

Rodrigues ACM, Gravato C, Quintaneiro C et al (2015) Life history and biochemical effects of chlorantraniliprole on Chironomus riparius. Sci Total Environ 508:506-513. https://doi.org/10. 1016/j.scitotenv.2014.12.021

Saito Y, Yamauchi R, Miyai K, Jinguji H (2014) Ecotoxicological assessment of nursery-box-applied chlorantraniliprole in micro paddy lysimeter. In: Proceedings of the 2014 Annual Meeting of The Japanese Society of Irrigation, Drainage and Rural Engineering. pp 312-313

Sánchez-Bayo F, Wyckhuys KAG (2019) Worldwide decline of the entomofauna: A review of its drivers. Biol Conserv 232:8-27. https://doi.org/10.1016/J.BIOCON.2019.01.020

Shimada T, Ogawa K, Miwa M, Saitou S (2004) Effect of rice agricultural pesticides on nontarget arthropods. Annu Rep Kanto-Tosan Plant Prot Soc 51:167-170

Suhling F, Befeld S, Häusler M et al (2000) Effects of insecticide applications on macroinvertebrate density and biomass in rice-fields in the Rhône-delta, France. Hydrobiologia 431:69-79. https://doi. org/10.1023/A:1004006422334

Suzuki E, Shinozaki T, Yamamoto E (2020) Causal diagrams: pitfalls and tips. J Epidemiol 30:153-162. https://doi.org/10.2188/jea. JE20190192

Uéda T (1988) Diversity in life history of the dragonfly Sympetrum frequens (Odonata: Insecta). Bull Ishikawa Agric Coll 18:98-110

Uéda T (1998) Dragonfly communities in paddy fields. In: Ezaki Y, Tanaka T (eds) Conservation of Wetland Environments: A View from Biological Communities. Asakura Book Co., Tokyo, pp 93-110

Venables W, Ripley B (2002) Modern applied statistics with S. 4th edn. Springer, New York

Wagner DL (2020) Insect declines in the Anthropocene. Annu Rev Entomol 65:457-480. https://doi.org/10.1146/annur ev-ento-011019-025151

Watanabe M, Matsuoka H, Taguchi M (2004) Habitat selection and population parameters of Sympetrum infuscatum (Selys) during sexually mature stages in a cool temperate zone of Japan (Anisoptera: Libellulidae). Odonatologica 33:169-179

Wilson AL, Watts RJ, Stevens MM (2007) Effects of different management regimes on aquatic macroinvertebrate diversity in Australian rice fields. Ecol Res 23:565-572. https://doi.org/10.1007/ s11284-007-0410-z 